\title{
Morning glory syndrome with contractile peripapillary staphyloma
}

\author{
G. CENNAMO, A. SAMMARTINO, AND F. FIORETTI
}

From the Department of Ophthalmology, 2nd Faculty of Medicine, University of Naples, Italy

SUMMARY We report a case of morning glory syndrome and discuss the clinical symptoms and echographic patterns. This malformation is attributed to the presence of an autonomous cholinergic mechanism situated at the posterior pole of the eye.

Morning glory syndrome is a congenital anomaly of the posterior pole which is characterised by an ectasia of the posterior pole of the fundus involving the optic disc. In addition there is a slightly protruding pigment ring in the peripapillary area, and nonbranching veins protrude in radial formation from the ectasia. Recognition of veins and arteries is always difficult. The peripheral retina appears normal. This unilateral malformation is often associated with myopic astigmatism and consequent diminution of vision. ${ }^{1}$

Correspondence to G. Cennamo. MD. Istituto di Clinica Oculistica. II Facoltà di Medicina e Chirurgia. Università degli Studi. 80131Napoli. Italy.

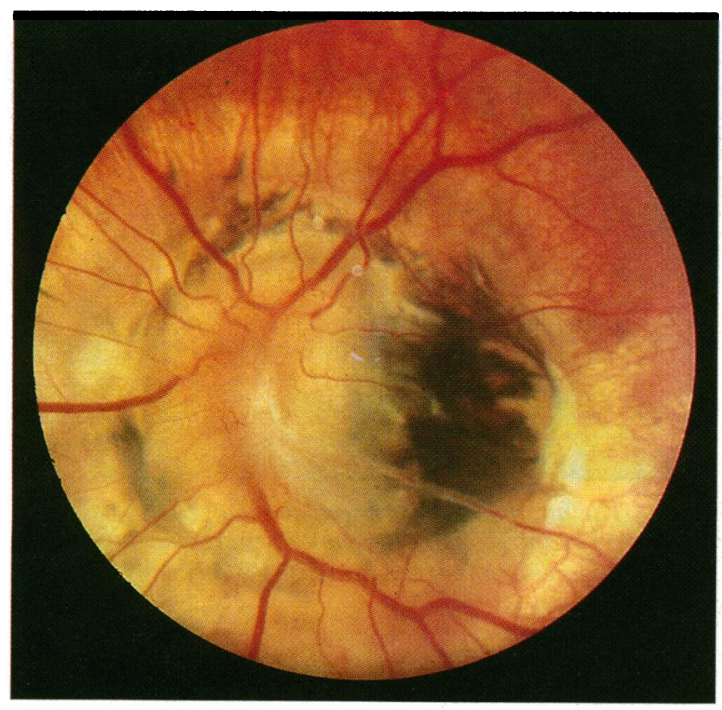

Fig. 1A
Cogan ${ }^{2}$ reported a case of morning glory syndrome with a folding of the retinal peripapillary tissue. Wise et al. ${ }^{3}$ Sugar and Beckman, ${ }^{4}$ Kral and Svarc. ${ }^{5}$ and Konstas et al. ${ }^{6}$ each reported on the contractility of a peripapillary staphyloma. The small number of reported cases of contractile morning glory syndrome induced us to publish the clinical and ultrasound data of a case we observed.

\section{Case report}

The patient, a man aged 20 , was first seen by one of us because of diminution of vision in the left eye. The

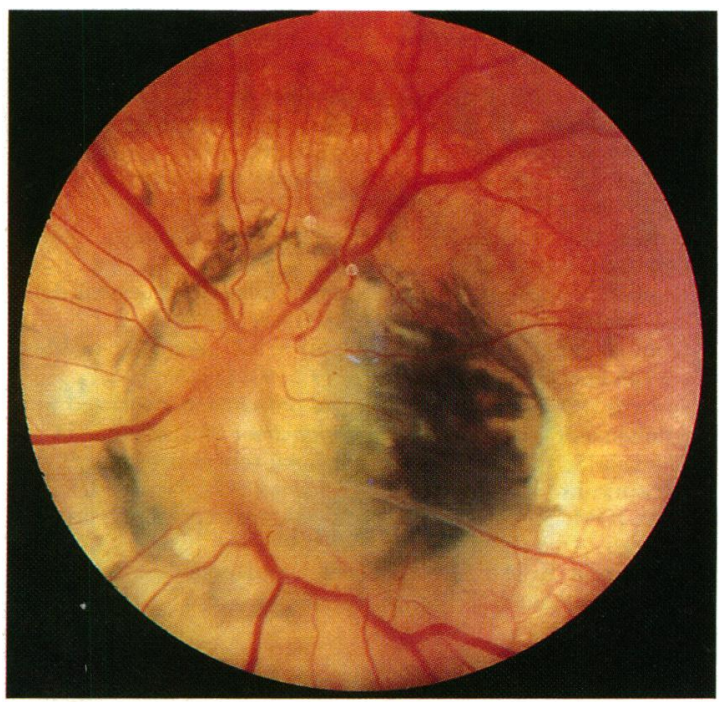

Fig. 1B

Fig. 1 A: Staphyloma in the stage of dilatation. B: First stage of contraction. C: Second stage of contraction. D: Final stage of contraction. 


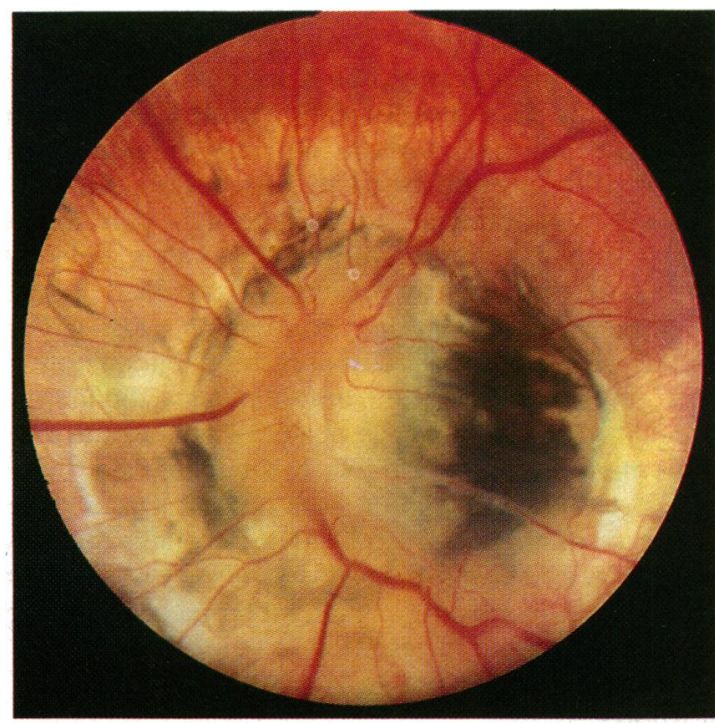

Fig. 1C

visual acuity of the right eye was $6 / 6$ without correction and that of the left eye $1 / 12$ with -4 sph and -2 cyl 180 . The right eye was healthy; in the left eye there was an absence of nystagmus. The anterior segment and refraction were also normal. Gonioscopically the chamber angle was open in all sectors, with no mesodermal residue. The fundus displayed a contractile peripapillary staphyloma of 2.5 disc diameters. At the centre was a cluster of white tissue from which thin veins protruded in a radial formation. A slightly raised peripapillary pigment ring was present. The macula and the surrounding retina appeared normal. (Fig. 1). Ophthalmodynamometry revealed no abnormality.

Ultrasound examination: standardised A-scan and

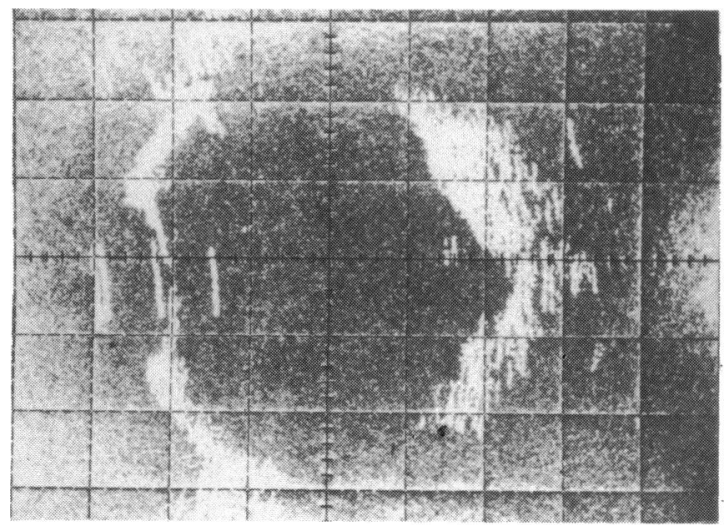

Fig. 2A

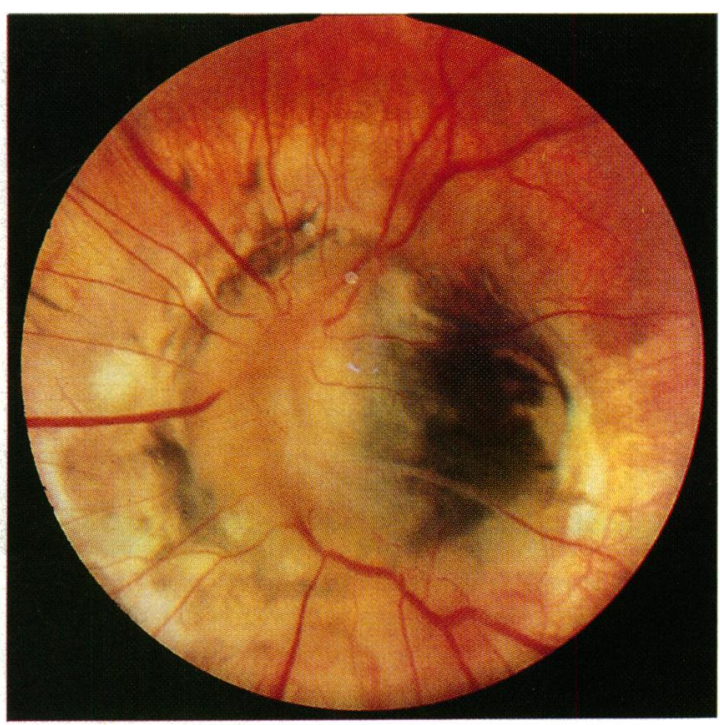

Fig. 1D

B-scan showed detachment of the posterior vitreous, no retinal detachment, and the presence of a contractile posterior staphyloma. Standardised A-scan showed that the extraocular muscles and the optic nerve were of normal dimensions; the length of the globe was $26 \mathrm{~mm}$ as measured by an immersion shell and by applying Ossoinig's method. ${ }^{7}$ Neither A nor B scan examination showed orbital or intraocular vascular anomalies.

In M-mode and B-scan examinations contractions of the peripapillary staphyloma were defined (Figs. $2 \mathrm{~A}$ and $\mathrm{B}, 3)$. During the ophthalmoscopic examination these contractions were of approximately 20 seconds duration, with a very irregular pattern which bore no relation to the respiratory rate or eye

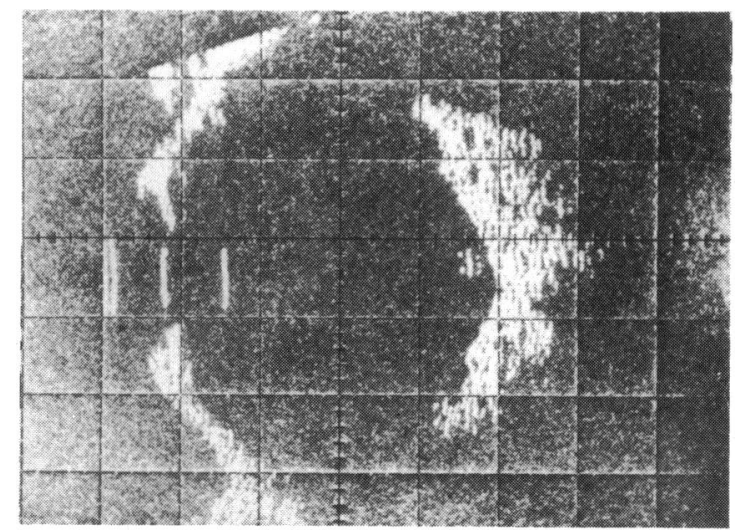

Fig. 2B

Fig. 2 A: B-scan echography showing the staphyloma in the stage of dilatation. B: B-scan echography showing the staphyloma in the stage of contraction. By this examination the depth of the staphyloma was $2.5 \mathrm{~mm}$. 


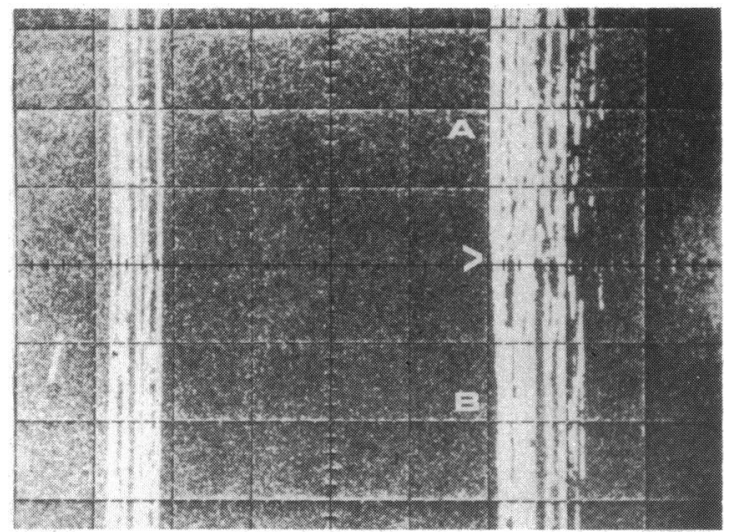

Fig. 3 M-mode echography showing the stage of contraction (A) and the stage of dilatation (B). Changes in retinal-choroidal thickness are easily noted $(>)$.

movements. These contractions were facilitated by finger pressure on 5 to 6 successive occasions and they were followed by rhythmic contractions of the staphyloma. A latent period then followed when finger pressure proved to be ineffective for approximately 30 minutes. Isometric and isotonic contraction tests of the inferior oblique did not modify the contraction pattern.

\section{Discussion}

Our clinical and ultrasound observation lead us to report this case under the name of morning glory syndrome. The contractile aspects of this syndrome are ill understood. Sugar and Beckman ${ }^{4}$ suggested the existence of a relationship between this mechanism and venous pressure variations during respiration. Our own observation on ophthalmodynamometry and those of Konstas et al. ${ }^{6}$ indicate this hypothesis is unsupportable. W. R. Lee ${ }^{8}$ noted a venous malformation in the optic nerve; but no such abnormality was disclosed by our ultrasound tests. Participation of the inferior oblique in the determinationn of the rhythmic contractions seems unlikely owing to the negative results we obtained in the isometric and isotonic contraction test. The Kral-Svarc hypothesis attributes this phenomenon to the presence of an autonomous cholinergic mechanism situated at the posterior pole of the eye. This might account for the fact that in our case, there was a latent period after 5 or 6 contractions. The presence of median myopia led us to believe that this particular case of morning glory syndrome was caused by a defect in closure of the embryonic cleft before the second month of gestation.

\section{References}

1 Brini A, Charton MN. Staphylome scléral péripapillaire avec ectopie postérieure de la papille (morning glory syndrome). J. Fr Ophtalmol 1980; 3: 323-6.

2 Cogan DG. Coloboma of the optic nerve with overly of peripapillary retina. BrJ Ophthalmol 1978: 62: 347-50.

3 Wise JB. Maclean AL. Gass JDM. Contractile peripapillary staphyloma. Arch Ophthalmol 1966: 75: 626-30.

4 Sugar HS. Beckman H. Peripapillary staphyloma with respiratory pulsation. Am J Ophthalmol 1969; 68: 895-7.

5 Kral K. Svarc D. Contractile peripapillary staphvloma. Am J Ophthalmol 1971: 71: 1090-2.

6 Konstas P. Katikos G. Vatakas LC. Contractile peripapillary staphyloma. Ophthalmologica 1976: 172: 379-81.

7 Ossoinig KC. Standardised echography: basic principles. clinical applications and results. In: Dallow RL. ed. Ophthalmic ultrasonography: comparative techniques. Intern Ophthalmol Clin Boston: Little. Brown. 1979: 19: 127-285.

8 Lee WR. Cited in Brini A. Charton MN. Banmgartner M. Staphyloma scleral peripapillaire avec ectopie postérieure de la papille (morning glory syndrome). J Fr Ophtalmol 1980: 3: 32.3-6. 